\title{
INTELLIGENT TRANSPORTATION SYSTEM OF SOLAR POWERED HYBRID ELECTRIC VEHICLES USING PATTERN MATCHING TECHNIQUES IN LABVIEW ENVIRONMENT
}

M. Pallikonda Rajasekaran

Professor, Dept. of ECE, Kalasalingam Academy of Research and Education,

Anand Nagar, Krishnankoil, (India).

E-mail: mpraja80@gmail.com

ORCID: https: / / orcid.org/0000-0001-6942-4512

N. Pothirasan

Research Scholar, Dept. of ECE, Kalasalingam Academy of Research and Education,

Anand Nagar, Krishnankoil, (India).

E-mail: gofire9988@gmail.com

ORCID: https://orcid.org/0000-0002-1254-0421

V. Muneeswaran

Assistant Professor, Dept. of ECE, Kalasalingam Academy of Research and Education,

Anand Nagar, Krishnankoil, (India).

E-mail: munees.klu@gmail.com

ORCID: https://orcid.org/0000-0001-8061-8529

Recepción: 11/11/2019 Aceptación: 08/01/2021 Publicación: 30/11/2021

\section{Citación sugerida:}

Rajasekaran, M. P., Pothirasan, N., y Muneeswaran, V. (2021). Intelligent transportation system of solar powered hybrid electric vehicles using pattern matching techniques in labview environment. $3 C$ Tecnología. Glosas de innovación aplicadas a la pyme, Edición Especial, (noviembre, 2021), 293-311. https:// doi.org/10.17993/3ctecno.2021.specialissue8.293-311 


\section{ABSTRACT}

While people driving a vehicle due to the distraction of drivers many persons suffer in accidents. The main reason behind these accidents is breaking the rules and not concentrates on the road signals. The main objective of this work is to build an IoT enabled intelligent transportation system. In this paper presented by utilizing a function there we make some links between the car and the signals present on the roads. The proposed system identifies the road sign with 98\% accuracy. By doing this we can minimize the accident that will happen. Additionally, by defining MPPT control algorithm we can control the BLDG motor inside the E-vehicle to consume less amount of power. And, by using color detection algorithm and shape algorithm, we can capture the road signal and we will save ourselves from accidents. In calculating the census of the death rate in 2017, we came to know that most of the people die in road accidents. They suffered to a condition that they cannot be able to lead their daily lives like normal persons. This work improvises the current infrastructure of autonomous vehicle and removes the hurdles that people facing by imparting automated algorithms.

\section{KEYWORDS}

Computer Vision, Road Vehicles, Transportation, Artificial Vision, Intelligent Transportation Systems, Lane Detection, Obstacle Detection. 


\section{INTRODUCTION}

By the survey of 2017, we came to know that most of the people died in the road accidents. These types of accidents make them have heavier wounds and lost their organs and even lead to death. People travel faster in road-side and are not just thinking about the effects of the accidents and spoil their whole future and people are not following the rules and drivers are not concentrating on the signals, these could made them lead to accidents. And, on the other-side, we noticed that because of using vehicles that run-in petrol and diesel, air pollution will happen and it creates pollution the environment. And people will suffer because of inhaling these polluted gases. While we are travelling in car, we could not easily identify the signals in the road-side. So, because of this, many accidents will happen and the people cannot be able to drive their own cars and they fixed their own cars and they fixed a driver to drive it.

Now-a-days, the cost of fuel is very high and there is no possible in using the cars which run in petrol/diesel. So, we can use E-vehicle instead of using fuel cars. By using E-vehicle, we can avoid the supply of the external battery. E-vehicles are good because we can avoid pollution by utilizing it. And, we can avoid the diseases caused by the environmental pollution. We can have a safe and simple journey in E-vehicle. By using vehicle, we must not spot on car repairs and damages because it was made by using small electronic devices. E-vehicle made our driving safe and secured. E-vehicle can be used by any person of oldage people, children and also by differently-abled people. Because it was designed with that much comfort ability. The amount of breakdown happens in E-vehicle is very low. It is designed as there we can take external sources like battery-operator, light and horns from the E-vehicle.

\section{RELATED WORKS}

This section gives a detailed description about the few notable works in the field of power electronics and hybrid vehicle design. The usage of computer vision is greatly emphasized by Bertozzi et al. (2002). Bertozzi et al. (2002) detected the application of pattern detection is being used in vital transport applications such as the detection of lanes, monitoring the mobility, etc. In his work, Emadi, Lee, and Rajashekara (2008), provided a brief review on 
the working characteristics of the circuit system and the involvement of power electronics systems in the construction of alternative vehicles. This conceptual analysis is helpful for analysing the effects of intrinsic behaviour of the lithium-ion batteries. The authors analysed the importance of parameters including the losses in the feeder, variance in load and the load factor for a PHEV charging in coordinated system.

Based the relativeness of the above three parameters a charging algorithm which inturn will reduce the unwanted charging behaviour in connected system of PHEV's was developed. The importance of image processing was discussed in very recent works ( $\mathrm{Li} e t$ al., 2019; Muneeswaran \& Rajasekaran, 2019). Pothirasan et.al. described the logical way interaction of Electric vehicles with the roadside signals through an efficient V-V and V-I communication interfaces (Pothirasan \& Rajasekaran, 2016, 2019). The usage of IoT in real time environment is depicted in Ramakala et al. (2017). Hadley and Tsvetkova (2009) described the statistical analysis of the market demand of PHEV as it provides alternative to the fuel system. Sun, Bebis, and Miller (2006) introduced an intelligent vehicular system by adding a pattern recognition technique that aids in detection of nearby vehicles and their speed range in iterative manner. Based on the knowledge gathered from these works the authors attempt to construct an intelligent transportation system with the support of LabVIEW environment.

\section{BLOCK DIAGRAM OF INTELLIGENT TRANSPORTATION SYSTEM}

We can run the BLDC Motor through the three phase inverter by means of converting DC (lead acid) into AC source. There are three methods available to charge the battery. 1. Solar Panel, 2. Regenerative braking system, 3. Using Grid. The power gained from solar panel and the power stored in the battery is given as input through MPPT Technique. Three phase inverter is working in double direction and the boost converter working in single phase. The overall block diagram of the proposed prototype explains the whole process. 


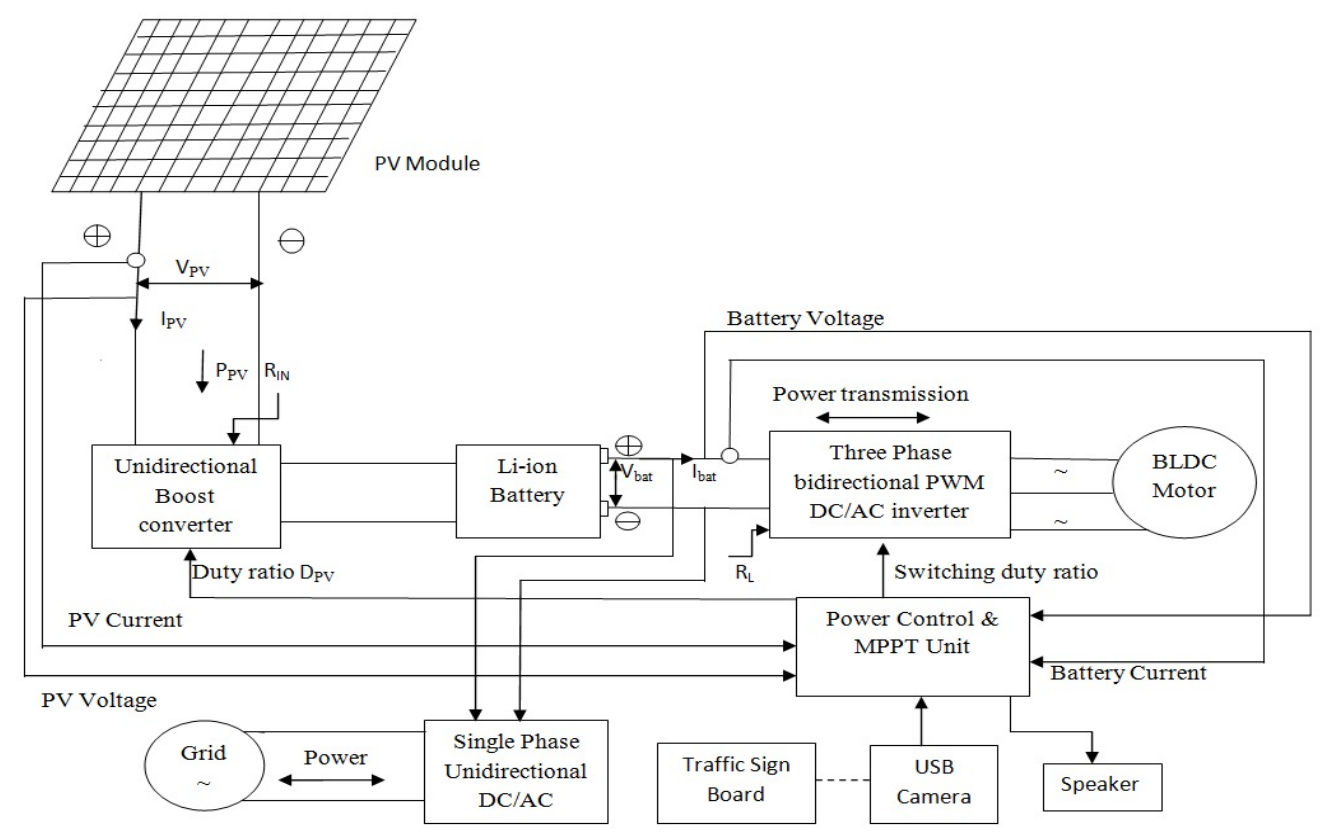

Figure 1. Block Diagram of Intelligent Transportation System.

Source: own elaboration.

The road side sign boards and traffic signals are captured by means of a camera fixed in the vehicles and it is displayed in the monitor to create awareness to the user. When the user failed to control the vehicle manually, the controller system itself will automatically control the vehicle after some period.

\section{MATERIALS AND METHODS}

\subsection{WORKING PRINCIPLE OF SOLAR PANEL}

There is an increment of shortage of electricity. It we use solar energy by all houses we can reduce the scarcity of electricity. The working of solar panel (photon) or particles of light to knock electrons force from atoms. By using this solar panel can generate power. The combination of two or more solar cells is Calles solar panel. In photo voltaic cell two silicones of semi-conducting material, usually by using silicon they using in microelectronics.

Generating current from photo voltaic cell is more required. Much like that magnetic field which occurs in conductors due to opposite poles of an electric occurs when opposite 
charges are separated. To get this field manufactures "dopc" silicon with other materials giving each silicon of sandwich positive or negative electrical charge. They include in to layer of silicon seed phosphorus and add extra electrons to negative charge layer. In the bottom layer boron and least amount of electrons are included to the positive charge. When sunlight's fall on photon the electron force is pushed through the electric field and electrons released through junction. The other components of the cell turn these electrons on couple to make usable power and gives to us. On the side of the cell a metal conductive plate was fixed and electrons are getting and sent through wires.

The electron flow that is taken from the point is called as sources of electricity. Recent researches told that while the manufacturing of ultrathin flexible solar cells 1.3 microns thicked 1/100th it is width of human hair, and having 20 times lesser amount of office sheet paper solar panel will made. In fact, the cells are so light that they can sit on top of a soup bubble and yet they produce energy with about as much efficiency as glass based solar cells. By using this kind of flexible solar cell, we can use it as aerospace technology or in wearable electronic. By using many types of solar panel solar power technology was presented.

Solar Thermal and concentrated solar power [CSP] were designed, with different fashion than photo voltaic solar panel. The energy produced from solar panel is generated through sunlight, heat water and air. In sunlight there is a natural nuclear reactor. The tiny particles released from these are called photons. The photons we are getting 93 million miles away from the sun and it reaches earth in 8.3 minutes. Currently, Photovoltaic power is lesser amount consumed in India solar energy is increasing and cost is dropping rapidly. On coming years, solar energy becomes the required energy to lead a normal life.

\subsection{BOOST CONVERTER DESIGN}

A Boost converter is a DC-DG power converter. It is a step-up voltage from its solar panel to battery. Diode and transistor acts as semiconductor devices in the boost conductor. On the other hand, capacitor and inductor acts as energy storage element and kept as two in combination. To reduce the voltage ripple inside and outside DC, A filter made of DC is fixed. Batteries, solar panels, rectifiers and DG generator are kept as the source of boost converter. In boost converter battery voltage is greater than solar panel voltage and in case of current battery current is lower than the source current. Since $(\mathrm{P}=\mathrm{VI})$ must be conserved. 


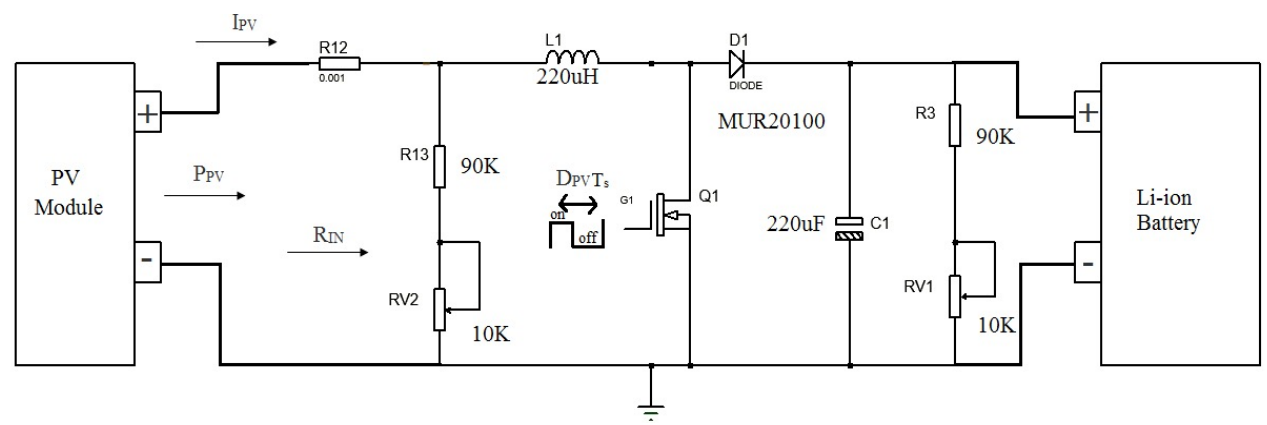

Figure 2. Boost Converter Design.

Source: own elaboration.

\subsection{CALCULATING THE DUTY CYCLE}

$$
D=1-\left[\frac{V_{I N(\min )} * \eta}{V_{O U T}}\right]
$$

Where D = Duty Cycle

$V_{I N(\min )}=$ minimum input voltage (this will lead to the maximum switch current)

$V_{\text {OUT }}=$ desired output voltage

\subsection{CHOOSING THE INDUCTOR}

$$
\mathrm{L}=\frac{\mathrm{V}_{\mathrm{IN}} *\left(\mathrm{~V}_{\text {OUT }}-\mathrm{V}_{\text {IN }}\right)}{\Delta \mathrm{I}_{\mathrm{L}} * \mathrm{f}_{\mathrm{S}} * \mathrm{~V}_{\text {OUT }}}
$$

Where $\mathrm{L}=$ Inductance in Henry

$V_{I N}=$ Typical input voltage, here, $0.9 \mathrm{~V}$

$f_{S}=$ minimum switching frequency of the converter. here, $960 \mathrm{kHz}$ (from datasheet)

$\Delta I_{L}=$ estimated inductor ripple current as discussed 


\subsection{OUTPUT CAPACITOR SELECTION}

$$
\mathrm{C}_{\text {OUT(min) }}=\frac{\mathrm{I}_{\text {OUT(max })} * \mathrm{D}}{\mathrm{f}_{\mathrm{s}} * \Delta \mathrm{V}_{\text {OUT }}}
$$

$C_{\text {OUT }(\min )}=$ minimum output capacitance needed

$I_{\text {OUT }(\max )}=$ maximum output current of the desired application

$D=$ Duty Cycle of the converter

$f_{S}=$ minimum switching frequency of the converter, $960 \mathrm{kHz}$

$\Delta V_{\text {OUT }}=$ desired output voltage ripple. here, $10 \mathrm{mV}$

$\Delta V_{\text {OUT (ESR) }}=\mathrm{ESR} * \mathrm{I}_{\mathrm{SW}(\max )}$

Where, $\Delta V_{\text {OUT }(\mathrm{ESR})}=$ additional output voltage ripple due to ESR.

\subsection{BRUSHLESS DC MOTOR}

The traditional DG motor has a mechanical commutated. A commutates is a suitable (mechanical or electrical) used to change the path of the current through two or more routes or (current through the windings) but BLDG motor seeks an external computation. This is realized by six IGBT power semiconductor switches to rout the path of the current through three winding in 6 directions.

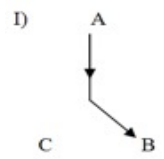

III)

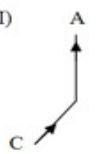

V)

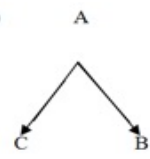

II)

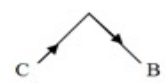

IV)

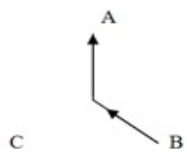

VI)

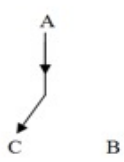

VII)

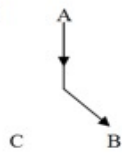

Figure 3. Winding Directions.

Source: own elaboration. 
In Figure 3, Figures I and VII are one and the same. Figure VII is the start of the second cycle and Figure 1 is the start of the first cycle. To change this sequence path of current (stator called as commutation). 6 IGBT switches are sequentially fixed in synchronization with the position of the poles of the permanent magnet of the rotor. The BLDC motor has a smaller size (lighter) in comparison with traditional DC motor because of the absence of the mechanical commutator and the electromagnetic (temporary magnets) field windings. Now a day's BLDC motor used in the domestic ceiling Fans.

\subsection{BATTERY CHARGING STATUS IDENTIFICATION}

In this project lead-acid batteries are used. The lead-acid battery consists of a small metal by which we can store the power through chemical reactions. Four numbers of 12V, 100 Ampere hour lead acid batteries connected in series $(12 \mathrm{~V} \times 4=48 \mathrm{~V})$. BLDC main motor has the voltage rating of $48 \mathrm{~V}$ so, four numbers of $12 \mathrm{~V}$ batteries are used. The capacitor of this motor is chosen as 750Watts that is $15 \mathrm{~A}$ at fuel rated load. If the efficiency of battery is considered as $80 \%$ than $100 \mathrm{Ah} \times 0.8=80 \mathrm{Ah}$. The duration of travel at fuel load will be 1.4 hours of fuel load. In this process positively charged particles are called as ion and negatively charged particles are called as electrons. In both cases of charging and discharging electrons flow in the opposite direction to the ions. The lab view software is used to identify the range of charging and discharging process of the battery. This can be monitored in a tablet computer is operated by $5 \mathrm{~V}$ Power supply which is another buck converter is to be used. This tablet will have $5000 \mathrm{mAh}$ [5Ah] battery. This can be charged by $1 \mathrm{~A}$ current rating at 5 Level. During charging process of any battery, that battery must be charged slowly (8 Hours) as per the charging time duration given by the supplier.

\subsection{CONSTRUCTION OF E-VEHICLE CONTROLLER DESIGN}

The myRIO controller plays a vital role in PHEV design. To safeguard the myRIO controller from reverse power effect, a driver board (IR2110) is designed. Driver boards are mostly used in the regulation of current flowing through a circuit or controls other factors such as the other devices or components in the circuit. The IR2110 Driver board is used to protect the myRIO (low power) from the High power IGBT circuit. This IR2110 also separates the gate signals of the upper IGBT from the lower IGBT signals, since the 
upper IGBT needs separate grounding for its gate signal with respectively emitter terminal. With the help of Hall Effect sensor, using myRIO controller we can identify the position of motor. Also running process of motor live forward/Reverse/Brake can be controlled by means of embedded "c" programming. It also consists of manual speed control device. To run BLDC motor, a three phase inverter and a power circuit can be used. It is explained in terms of graphical diagram in given above Figure 4.

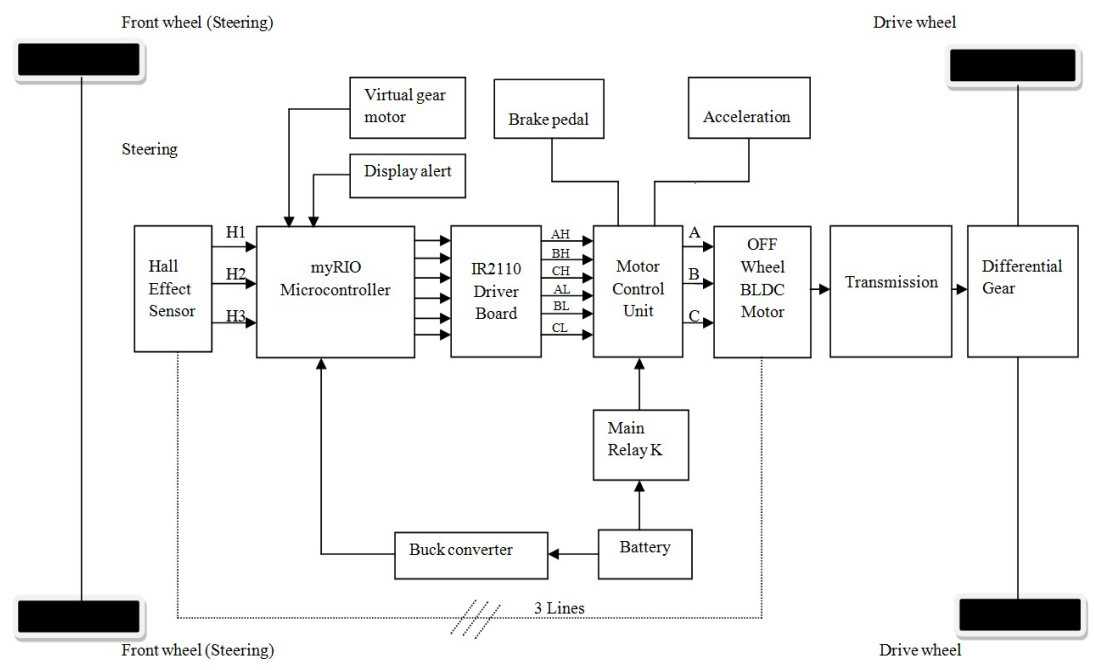

Figure 4. PHEV Design.

Source: own elaboration.

\section{CONSTRUCTIONAL DETAILS OF SOLAR POWERED E-VEHICLE}

To bring the traffic sign board signals to vehicle vision sensor is required. Also are wanted to come across image pre-processing. Board captured by vision sensor are all not in a same quantity. In image pre-processing the original image brightness, contrast, pixel of image and set in constant quantity. By using LabVIEW icons like geometry, lookup table we can set. Using geometry icon IV, we can propose of Re sampling technique. Also, by using lookup table we can make pixel intensity to good quality. Because of this image can be set in same quality and same quantity. There are four major works in intelligent transportation system of PHEV they are Detection, Recognition, BLDC motor controlling and voice output. Here we proposed is, by using old method of classification we detect the traffic sign board. After the recognition process, we started controlling the BLDC motor. For the unidentified 
things we used voice output. In our intelligent transportation system, the processes we proposed are follows:

1. Traffic sign board of Detection, Extraction, Recognition.

2. To recognition of some Traffic sign board to control the BLDG motor.

3. Traffic sign board of to deliver the voice output.

In the case, if it not been identified it makes human to deliver the voice output. In my paper to recognize the traffic sign board, I have used two techniques, one is deep learning of the sample pattern and the other is object pattern and I approached two process one is OCR (Object Character Recognition) and other is geometric pattern matching. The modifying Hough transform of circular by doing detection process. Shape detection plays important role in detecting the sign boards. We can filter the unwanted substance came inside by utilizing colour thresholding. We, detect the sign board s are in circular and triangular shape and in red, black and white in colour of background. So, this detection process is classified into shape detection, colour thresholding detection.

\subsection{SHAPE DETECTION}

By utilizing shape detection algorithm, we can detect the circular board. In sign board the circular diameter is $15 \mathrm{~cm}-30 \mathrm{~cm}$ measure and it was designed by range. But some sign boards are not detected. So, it unfortunately stopped the detection process so the undetected sign board are detected by using colour thresholding technique triangular sign boards are by geometric algorithm matched by changed into template create by detected. This colour thresholding design set at a local range. This range reference is done by online image. Segment was settled according to only red outline was designed. By using filter, we make better quality of segmentation and equalized. After colour thresholding by shape detection we detected to triangular shape board we applied thresholding we attained segmentation segmented boards triangular shape was by geometric algorithm. we template created and matched and finally detected.

\subsection{EXTRACTION OF SIGN BOARDS}

We set co-ordinate the detected sign board and extract sign board from over all image and using detected boards mask location was settled and extracted. 


\subsection{RECOGNITION OF SIGN BOARDS}

Inside the extracted sign boards to recognize the information three types are utilized.

1. Threshold segmentation.

2. Canny edge filtering.

3. Geometric algorithm.

Using a local threshold algorithm called NI back threshold and using dark object technique are done segment. Dark object range is locally set by the NI block algorithm. By Canny edge filtering the applied NI block image edges are filtered and equalization is by edge based geometric algorithm template created and by matching the edges we can recognize.

\section{CONSTRUCTION OF INTELLIGENT TRANSPORTATION SYSTEM AND HARDWARE EXPERIMENTAL VERIFICATIONS:}

In the proposed PHEV vehicle, we can charge the battery, using the variable voltage and current obtained from the solar panels with the help of boost converter. By converting a three phase inverter, we can run the BLDC motor. MPPT control algorithm can be used for closed loop control system. It consists of input 48V, 26Ah battery, solar panel and camera. The purpose of the camera is to capture the roadside signals. The proposed intelligent transportation system of PHEV is considered a battery bank of 48V; 100A/h and the solar panel of $150 \mathrm{~W}$ are taken place.

Power revealed from the solar panel changes according to level of sunlight passes on it. The variable current and variable voltage derived from the PV module and the same derivation from variable battery voltage and variable battery current both given as an input for power control \& MPPT control. By doing this, we can adjust the PWM duty ratio and we will receive a constant voltage and constant current. To charge 100Ah lead acid battery we need maximum 10 hours. But for charging we require 10Ampere per hour. (10Ampere x 10hour $=100 \mathrm{Ah})$.

If the current receiving by the battery exceeds 10Ampere the battery get blast or its size become enlarged. Also, if the battery gets fully charged it was denoted in the LCD display. In some case, if we do identify it buzzers every 30 minutes. For this identification a program 
is set. By these proper handling methods, we can increase the battery's life. In PHEV, myRIO controller has a unique position. PWM ratio revealed from the myRIO Controller with the help of MPPT controller it provides constant current and constant voltage to the battery. By this activity, battery will charge in the efficient manner.

To measure the voltage, drop in the solar panel and boost converter a potential divider circuit is used. By utilizing this, a loop voltage is sent as an analog input for myRIO converter. In other hand, to measure the current shunt present inside the solar panel and boost converter 1NA168 integrated circuit is used. By utilizing this current is send as closed loop for the myRIO controller. By giving voltage loop and current loop as input we can receive a constant voltage \& constant current. By processing this we can perfectly charge the battery. By presenting battery power as an input to the three phase inverter we can run the BLDC motor. Information in traffic sign board changes into the way inside PHEV vehicle is called as vehicle to infrastructure. By using of myRIO controller keeping Vision mission inside the NI labview and using the process of image acquisition we can identify the traffic sign board and the information inside this can be captured by camera.

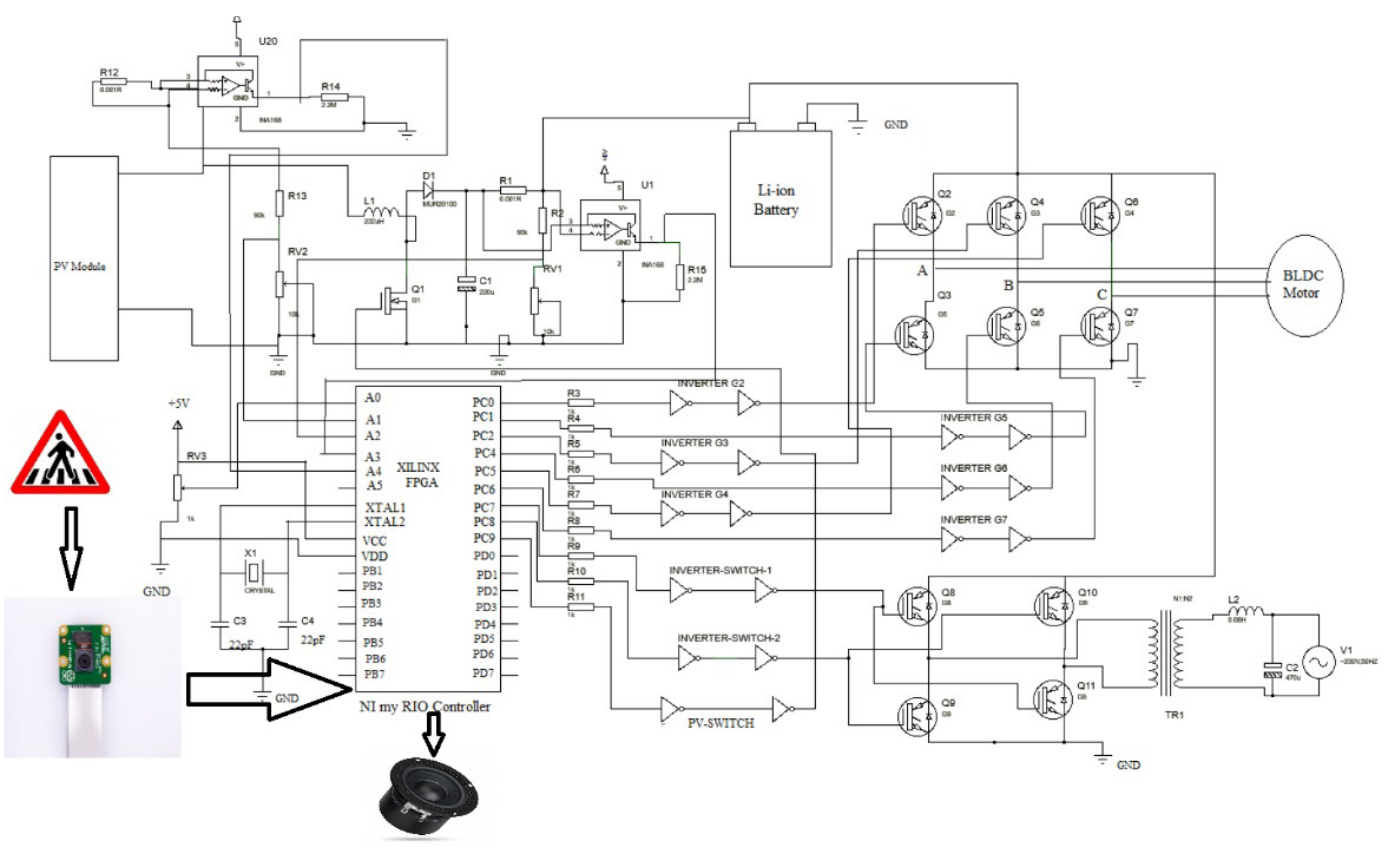

Figure 5. Integration of PHEV Design and V2R Communication.

Source: own elaboration. 
Lastly in PHEV by utilizing display and motor control we can prevent from accidents because of using LabVIEW software image acquisition process is held rapidly. Information denoted on traffic sign board gives a voice alert inside the warning. A buzzer strikes loudly. If he/she drives by not knowing this BLDC motor would be control automatically. By displaying road signals on the laptop and driver can easily identify the signals. To bring the traffic board signals to vehicle vision mission is required. This type of intelligent PHEV vehicle and designed of using this only on smart cities.

\section{RESULTS}

The front panel design for effective recognition of road sign is implemented using LabVIEW. It recognizes the character earlier and the time taken is also reduced and it is shown in Table 1 .

Table 1. Time taken for Sign Board Recognition.

\begin{tabular}{|c|c|c|}
\hline S.No & Pattern & Time taken (in Secs) \\
\hline 1 & Road Sign for One way & 2.031 \\
\hline 2 & Road Sign for $20 \mathrm{Km}$ & 1.033 \\
\hline 3 & Road Sign for U turn & 2.421 \\
\hline 4 & Road Sign for Speed Braker & 2.228 \\
\hline
\end{tabular}

Source: own elaboration. 

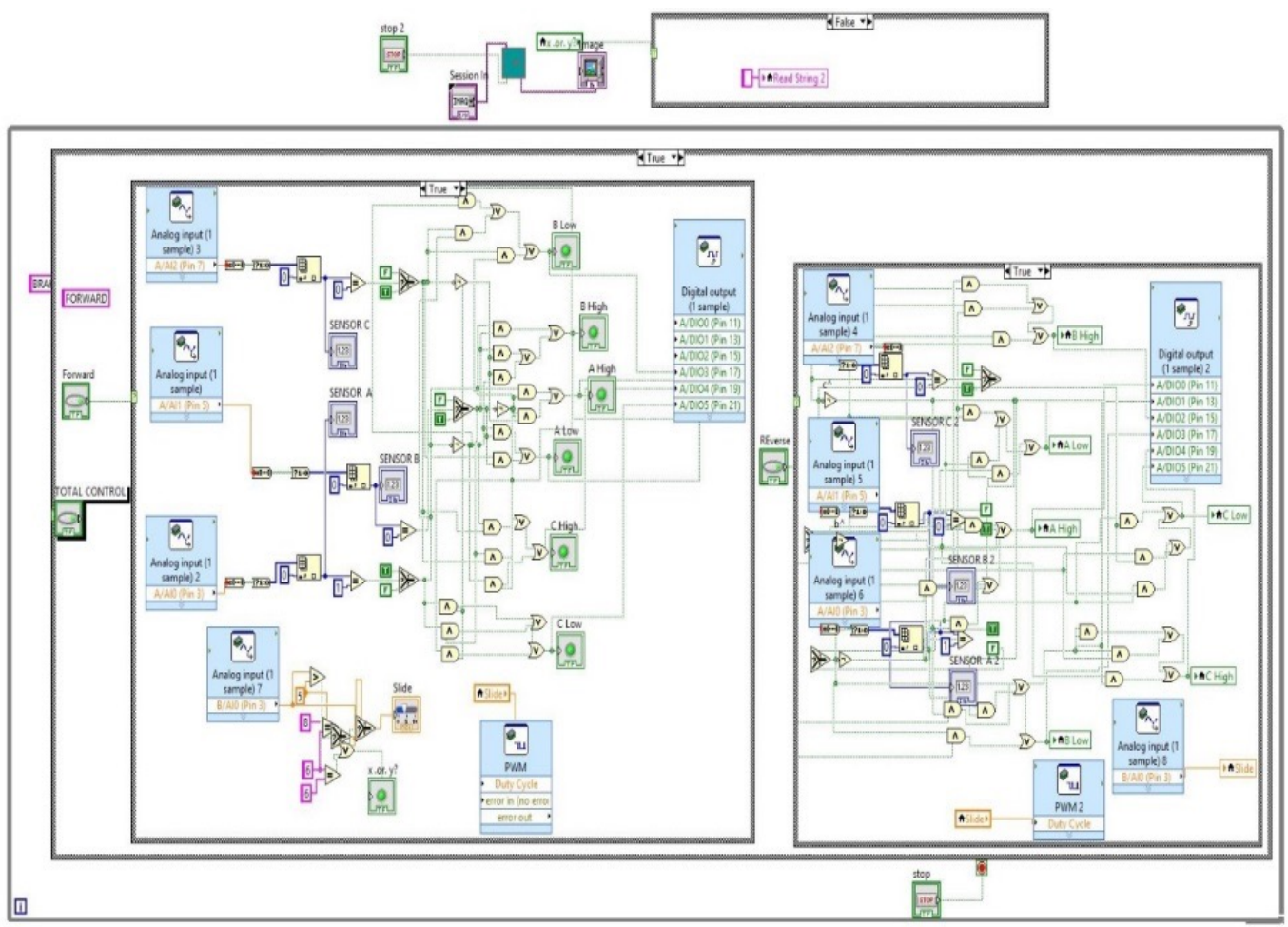

Figure 6. Simulation experiment done in LabVIEW Environment (Block Diagram).

Source: own elaboration.

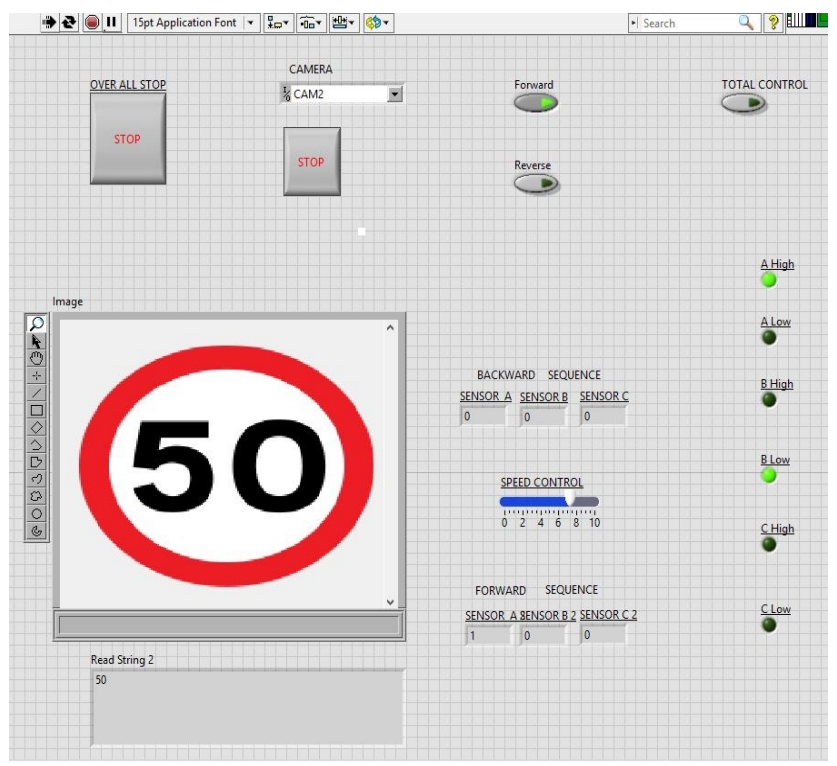

Figure 7. Simulation experiment done in LabVIEW Environment (Front Panel).

Source: own elaboration. 


\section{CONCLUSIONS}

In this paper, a brief solution to a rising societal problem in designing intelligent transportation system was discussed. The proposed recognition system efficiently recognizes the road sign accurately with the help of thresholding and edge detection algorithm. The defined comprehensive and integrated system approach, referred to as intelligent transportation systems (ITS), links the vehicle, the infrastructure, and the driver to make it possible to achieve more mobile and safer traffic conditions by using state-of-the-art electronic communication and computer-controlled technology. This work will be helpful for automated vehicular transportation. The future work of this system includes building automated decision making based on the detected and recognized sign boards.

\section{ACKNOWLEDGEMENT}

The authors thank the Department of ECE, Kalasalingam Academy of Research and Education, for permitting them to use the computational facilities available in the Centre for Research in Signal Processing and VLSI Design which was established with the support of the Department of Science and Technology (DST), New Delhi under FIST Program in 2013 (Reference No: SR/FST/ETI-336/2013 dated November 2013).

\section{REFERENCES}

Bertozzi, M., Broggi, A., Cellario, M., Fascioli, A., Lombardi, P., \& Porta, M. (2002). Artificial vision in road vehicles. Proceedings of the IEEE, 90(7), 1258-1271. https://ieeexplore.ieee.org/document/ 1032807

Emadi, A., Lee, Y. J., \& Rajashekara, K. (2008). Power electronics and motor drives in electric, hybrid electric, and plug-in hybrid electric vehicles. IEEE Transactions on industrial electronics, 55(6), 2237-2245. https://ieeexplore.ieee.org/document/4493430

Hadley, S. W., \& Tsvetkova, A. A. (2009). Potential impacts of plug-in hybrid electric vehicles on regional power generation. The Electricity fournal, 22(10), 56-68. https:// doi.org/10.1016/j.tej.2009.10.011 


\section{Li, L., Muneeswaran, V., Ramkumar, S., Emayavaramban, G., \& Gonzalez, G. R.} (2019). Metaheuristic FIR filter with game theory based compression technique-A reliable medical image compression technique for online applications. Pattern Recognition Letters, 125, 7-12. https://doi.org/10.1016/j.patrec.2019.03.023

Muneeswaran, V., \& Rajasekaran, M. P. (2019). Automatic segmentation of gallbladder using intuitionistic fuzzy based active contour model. In Microelectronics, Electromagnetics and Telecommunications (pp. 651-658). Springer, Singapore.

Muneeswaran, V., \& Rajasekaran, M. P. (2019). Local contrast regularized contrast limited adaptive histogram equalization using tree seed algorithm - an aid for mammogram images enhancement. In Smart intelligent computing and applications (pp. 693-701). Springer, Singapore.

Pothirasan, N., \& Rajasekaran, M. P. (2016). Automatic vehicle to vehicle communication and vehicle to infrastructure communication using NRF24L01 module. In 2016 International Conference on Control, Instrumentation, Communication and Computational Technologies (ICCICCT) (pp. 400-405). IEEE.

Pothirasan, N., \& Rajasekaran, M. P. (2019). Retrofitting of Sensors in BLDC Motor Based e-Vehicle-A Step Towards Intelligent Transportation System. In Smart Intelligent Computing and Applications (pp. 61-69). Springer, Singapore.

Pothirasan, N., Rajasekaran, M. P., \& Muneeswaran, V. (2018). Real time reactive power compensation for battery/photovoltaic hybrid power source for internet of hybrid electric vehicle system. Cognitive Systems Research, 52, 473-488. https://doi. org/10.1016/j.cogsys.2018.07.030

Ramakala, R., Thayammal, S., Ramprakash, A., \& Muneeswaran, V. (2017). Impact of ICT and IOT Strategies for Water Sustainability: A Case study in Rajapalayam-India. In 2017 IEEE International Conference on Computational Intelligence and Computing Research (ICCIC) (pp. 1-4). IEEE. 
Sun, Z., Bebis, G., \& Miller, R. (2006). On-road vehicle detection: A review. IEEE transactions on pattern analysis and machine intelligence, 28(5), 694-711. https://ieeexplore. ieee.org/document/1608034 
